\title{
KARAKTERISTIK KIMIAWI FLY ASH BATU BARA DAN POTENSI PEMANFAATANNYA SEBAGAI BAHAN PUPUK ORGANIK
}

\author{
Sari Widya Utami \\ Politeknik Negeri Cilacap \\ Email: sariwidyautami@gmail.com
}

\begin{abstract}
The purpose of the research was to study the content of chemistry of fly ash and the its potention of fly ash as the matterial of organic fertilizer. The research was conducted by mixing fly ash with some organic matterials with comparison 1:9. The materials that used in this research were 10\% of fly ash of PLTU Karang kandri Cilacap, 40\% of dusk of ripsaw, 20\% of dung of laying pullet, 20\% of leguminosa leaves, and $10 \%$ of 'Ares' of banana stalk. All organic fertilizer materials were mixed and done incubation for 3 weeks. The result of analysis was compared to the standard of organic fertilizer quality according to the regulation of Agriculture Department (Permentan) No. 70 year 2011. The result of the research showed that the main composer of fly ash that used was iron (71.2\%), silicate (16he ratio of C/N of organic fertilizer which was 24.77. The fertilizer had low content of macro nutri,2\%) and alumunium (7.67\%).The ph value of the fertilizers which made was alkalis i.e 8.52. T ent i.e total- N (1.36\%), total-P (1.13\%) and total-K $(2.23 \%)$.The heavy metal content of the fertilizer was low category, i.e 3.38 pmm of As, $0.53 \mathrm{ppm}$ of $\mathrm{Cd}, 0.005 \mathrm{ppm}$ of $\mathrm{Hg}$ and $8.18 \mathrm{ppm}$ of $\mathrm{Pb}$.
\end{abstract}

Keywords: fly ash, organic fertilizer, heavy metal, potention

\section{PENDAHULUAN}

Kegiatan PLTU sebagai penyumbang energi listrik menyisakan limbah dalam jumlah yang sangat besar setiap tahunnya. Berdasarkan data komposisi data energi listrik per jenis energi primer Indonesia diproyeksikan penggunaan batu bara mencapai $56.91 \%$ pada tahun 2016 dan mengalami kenaikan sebesar $2.15 \%$ pada tahun 2017 yaitu mencapai 59.06\% (Kementerian ESDM, 2016). Departemen Energi Amerika Serikat melaporkan produk pembakaran batu bara menghasilkan limbah fly ash sebanyak 52\% (Brown et al., 2015). Peningkatan penyediaan energi listrik melalui pembangunan PLTU baru, berkorelasi dengan peningkatan jumlah limbah fly ash yang dihasilkan. Ardha (2003) menyebutkan bahwa jika limbah fly ash tidak dimanfaatkan secara maksimal maka akan menjadi masalah pencemaran lingkungan. Dampak dari hal tersebut yaitu tempat pembuangan akan memerlukan lahan semakin luas dan berpengaruh juga terhadap efek cemarannya.

Pemanfaatan limbah fly ash sudah dilakukan dalam beberapa bidang keteknikan. Salah satunya limbah fly ash sudah dimanfaatkan dalam bidang teknik sipil, seperti sebagai bahan pencampur beton. Maryoto (2008) menyampaikan pemanfaatan fly ash pada konstruksi beton dapat meningkatkan mutu dan ketahanan beton di daerah agresif. Hai ini disebabkan terjadi reaksi pozolanik yang akan mengikat kapur bebas oleh silikat fly ash, sehingga membentuk permukaan yang lebih padat dan kedap air. Menurut Brown et al (2015), fly ash dapat menyementasi secara mandiri ketika terhidrasi.

Pemanfaatan limbah dalam bidang pertanian sudah banyak dilakukan, khususnya limbah organik. Pemanfaatan limbah sebagai pupuk organik seperti limbah biogas (Utami dkk., 2014), limbah 
sampah kota (Yazdanpanah et al., 2016), limbah abu sekam dan abu serbuk gergaji (Zuraida, 2013) dan berbagai limbah lainnya mampu meningkatkan status kesuburan tanah dan mendukung produktivitas tanaman. Sedangkan, pemanfaatan fly ash dalam bidang pertanian terutama sebagai bahan pupuk organik di Indonesia belum banyak dilakukan walaupun ketersediaannya melimpah. Oleh karena itu, penelitian ini dilaksanakan untuk mengetahui karakteristik kimiawi penyusun limbah fly ash batu bara dan bagaimana potensi fly ash sebagai campuran bahan pupuk organik.

\section{METODE}

Bahan pupuk organik yang sudah disiapkan dimasukan ke dalam wadah/tong sesuai dengan rancangan perbandingan proporsi bahan. Perbandingan banyaknya fly ash dengan bahan organik lain yaitu 1:9. Adapun komposisi bahan pupuk tersebut yaitu fly ash sebanyak $10 \%$, ares batang pisang $10 \%$, daun leguminosa $20 \%$, kotoran ayam petelur $20 \%$ dan serbuk gergaji sebanyak 40\%. Semua bahan dicampur dan diaduk hingga rata. Proses dekomposisi dipercepat dengan penambahan EM-4. Proses pengomposan berlangsung selama 3 minggu setelah pencampuran bahan.

Analisis komposisi fly ash dilakukan dengan menggunakan alat XRF yang dilaksanakan di Laboratorium Teknik Geologi Fakultas Teknik Unsoed Purwokerto. Penyusun dominan fly ash diurutkan berdasarkan dari urutan dengan komposisi terbesar. Unsur yang diuji yaitu unsur dominan penyusun fly ash seperti $\mathrm{Al}_{2} \mathrm{O}_{3}, \mathrm{SiO}_{2}, \mathrm{Fe}_{2} \mathrm{O}_{3}, \mathrm{MgO}$ dan $\mathrm{CaO}$.

Analisis kimia pupuk organik dilaksanakan di laboratorium Tanah fakultas Pertanian Unsoed Purwokerto dan LPPM Universitas Gadjah Mada. Parameter pupuk organik yang diuji yaitu $\mathrm{pH}\left(\mathrm{H}_{2} \mathrm{O}\right)$, C-organik, $\mathrm{N}, \mathrm{P}, \mathrm{K}$ dan kandungan logam berat antara lain $\mathrm{As}, \mathrm{Hg}$, $\mathrm{Pb}$, dan $\mathrm{Cd}$. Analisa logam berat $\mathrm{As}, \mathrm{Cd}$ dan $\mathrm{Pb}$ menggunakan metode AAS, sedangkan analisa $\mathrm{Hg}$ dengan menggunakan metode analisa merkuri.

\section{HASIL DAN PEMBAHASAN}

\section{Komposisi Utama Penyusun Fly ash}

Hasil analisa laboratorium fly ash PLTU Karang Kandri yang digunakan mempunyai beberapa komposisi kimia yang disajikan pada Tabel 1. Tabel 1 menunjukkan bahwa unsur terbanyak pada fly ash yang digunakan adalah besi yaitu mencapai $71.2 \%$. Silikat dan alumina jauh lebih sedikit dibandingkan besinya yaitu sebesar $16.2 \%$ dan $7.67 \%$. Hasil tersebut berbeda dengan beberapa penelitian sebelumnya yang melaporkan (Umardani dan Sudrajat, 2007; Widyaningsih et al, 2011) bahwa unsur terbanyak menyusun fly ash berupa silikat.

Perbedaan komposisi fly ash disebabkan perbedaan jenis batu bara yang digunakan. Jenis fly ash dapat ditentukan berdasarkan perbandingan kandungan beberapa unsurnya. Pengklasifikasian fly ash ke dalam kelas Batuminous dan Lignit di dasarkan pada perbandingan $\mathrm{Fe}_{2} \mathrm{O}_{3}$ dengan jumlah $\mathrm{CaO}$ dan $\mathrm{MgO}$. Apabila $\mathrm{Fe}_{2} \mathrm{O}_{3}$ lebih besar dari $\mathrm{CaO}$ dan $\mathrm{MgO}$ maka digolongkan menjadi kelas Batuminous, sedangkan apabila $\mathrm{Fe}_{2} \mathrm{O}_{3}$ lebih kecil dari $\mathrm{CaO}$ dan $\mathrm{MgO}$ maka digolongkan menjadi kelas Lignit. Berdasarkan Tabel 1, maka fly ash yang digunakan merupakan kelas Batuminous.

Tabel 1 Urutan unsur penyusun fly ash PLTU Karangkandri Cilacap (2017)

\begin{tabular}{lcc}
\hline \multicolumn{1}{c}{ Parameter } & Satuan & Hasil \\
\hline $\mathrm{Fe}_{2} \mathrm{O}_{3}$ & $\%$ & 71.2 \\
$\mathrm{SiO}_{2}$ & $\%$ & 16.2 \\
$\mathrm{Al}_{2} \mathrm{O}_{3}$ & $\%$ & 7.67 \\
$\mathrm{CaO}$ & $\%$ & 2.79 \\
$\mathrm{MgO}$ & $\%$ & 1.05 \\
\hline
\end{tabular}


Karakteristik Kimia Pupuk Organik + Fly ash

Data Tabel 2, menunjukkan nilai $\mathrm{pH}$ pada kisaran 8-9 yang mengindikasikan pupuk organik yang dihasilkan bersifat basa, dan tidak berpotensi menyebabkan penurunan $\mathrm{pH}$ tanah apabila nanti diaplikasikan ke tanah. Biasanya Selain itu nilai $\mathrm{pH}$ termasuk masih berada pada standar mutu organik (Permentan no 70 tahun 2011). Nilai pH pada kisaran tersebut mengindikasikan kemampuan buffering yang tinggi pula. Hal ini menjadi salah satu indikator pengaruh fly ash dalam peningkatan nilai $\mathrm{pH}$, dimana fly ash memberikan nilai $\mathrm{pH}$ antara 8-9 (Garavaglia dan Caramuscio,1994).

Tabel 2 Hasil analisa uji pupuk organik yang ditambahkan fly ash

\begin{tabular}{llccc}
\hline No & Parameter & Satuan & Hasil & $\begin{array}{c}\text { Standar kualitas } \\
\text { pupuk* }\end{array}$ \\
\hline 1. & $\mathrm{pH} \mathrm{H}_{2} \mathrm{O}$ & $\%$ & $4-9$ \\
2. & C-organik & $\% .52$ & $\geq 12$ \\
3. & $\mathrm{N}$ total & $\%$ & 33.71 & $>4$ \\
4. & $\mathrm{C} / \mathrm{N}$ & $\%$ & 1.36 & $15-25$ \\
5. & $\mathrm{P}_{2} \mathrm{O}_{5}$ total & 24.77 & $>4$ \\
6. & $\mathrm{~K} 2 \mathrm{O}$ total & $\%$ & 1.13 & $>4$ \\
7. & $\mathrm{As}$ & $\mathrm{Ppm}$ & 2.23 & $\leq 10$ \\
8. & $\mathrm{Cd}$ & $\mathrm{Ppm}$ & 3.38 & $\leq 2$ \\
9. & $\mathrm{Hg}$ & $\mathrm{Ppm}$ & 0.53 & $\leq 1$ \\
10. & $\mathrm{~Pb}$ & $\mathrm{Ppm}$ & 8.005 & $\leq 50$ \\
\hline
\end{tabular}

Keterangan : *Standar kualitas pupuk yang digunakan berdasarkan Permentan No 70 Tahun 2011

Kadar C-organik cukup tinggi, dengan kandungan $\mathrm{N}$ total kurang dari $4 \%$. Nilai $\mathrm{C} / \mathrm{N}$ sudah memenuhi standar mutu organik pada pupuk tersebut menunjukkan bahwa pupuk yang dihasilkan sudah matang (15-25). Nisbah $\mathrm{C} / \mathrm{N}$ pupuk organik yang diberi fly ash berada pada kisaran nilai tersebut, menunjukkan bahan organik sudah terdekomposisi atau kompos tersebut sudah matang. Pupuk organik yang sudah matang mengindikasikan ketiadaan dari Pytotoxin (Komilis and Tziouvaras, 2009), sehingga aman untuk diaplikasikan pada tanah dan tanaman.

Kandungan hara makro seperti N,P dan K kurang dari 4\% (Tabel 2). Hal tersebut memang umum terjadi dimana kebanyakan pupuk organik hanya mengandung sedikit hara dengan sifatnya yang slow release. Rendahnya kandungan $\mathrm{N}$ total tersebut diduga tidak dipengaruhi oleh adanya penambahan fly ash. Hal tersebut didasarkan pada tidak ditemukannya kandungan $\mathrm{N}$ pada fly ash. Fly ash yang merupakan limbah dari batubara, tentunya sudah mengalami proses pembakaran dengan suhu tinggi, sehingga unsur $\mathrm{N}$ tidak ditemukan. Ketiadaaan unsur $\mathrm{N}$ pada fly ash mengindikasikan bahwa $\mathrm{N}$ total pada pupuk berasal dari bahan pencampur lain yaitu daun leguminosa maupun dari kotoran ayam petelur. Hal tersebut berimplikasi pada kandungan total $\mathrm{N}$ yang rendah yaitu $1.36 \%$.

Penggunaan fly ash sebagai bahan pencampur bahan pupuk organik juga tidak menunjukkan adanya pengaruh yang signifikan terhadap besarnya kandungan $\mathrm{P}$ total pupuk. Kandungan $P$ total pupuk yang rendah yaitu $1.13 \%$ diduga berasal bukan dari penambahan fly ash, yang berkorelasi dengan tidak masuknya $\mathrm{P}$ sebagai penyusun dominan fly ash (Tabel 1). Rendahnya nilai $\mathrm{P}$ diduga karena sumber unsur tersebut proporsinya kecil yaitu ares 
batang pisang (10\%). Ares batang pisang merupakan salah satu sumber $\mathrm{P}$ walau dalam jumlah yang kecil. Seperti yang disampaikan oleh Saraiva et al. (2012), ares batang pisang mempunyai kandungan $\mathrm{P}$ total pada kisaran 0.2-0.4\%.

Kandungan $\mathrm{K}$ total pupuk juga tidak dipengaruhi oleh penambahan fly ash. Akan tetapi besarnya kandungan $\mathrm{K}$ total pada pupuk lebih besar dibandinganya jumlah $\mathrm{P}$ totalnya. Kandungan $\mathrm{K}$ total sebesar $2.23 \%$ yaitu 2 kali dibandingkan jumlah P totalnya. Sumber K pada pupuk tersebut diduga berasal dari serbuk gergaji, dimana unsur $\mathrm{K}$ merupakan unsur penyusun ke-2 yang dominan pada material tersebut yaitu sebesar $31 \%$ (Hasil analisa, 2017 dan data tidak dipublikasikan). Selain itu jumlah serbuk gergaji yang sebesar $20 \%$ dari total material bahan organik yang digunakan menjadi salah satu faktor yang mempengaruhi jumlah $\mathrm{K}$ total pada pupuk yang dihasilkan.

Penggunaan fly ash sebagai bahan pupuk organik tidak memberikan dampak yang negatif pada pupuk, walaupun tidak dapat meningkatkan besarnya kandungan hara makro pupuk. Hal ini dapat dilihat dari besarnya kandungan logam berat pada pupuk seperti As, Cd, hg dan $\mathrm{Pb}$ (Tabel 2). Kadar As pada pupuk yaitu 1/3 dari batas maksimal yang diizinkan pada standar mutu pupuk organik. Hasil pengujian untuk unsur $\mathrm{Cd}$ juga menunjukkan hasil yang positif yaitu hanya $1 / 4$ dari batas maksimal yang diizinkan. Demikian juga untuk unsur $\mathrm{Pg}$, dimana hasil analisa menunjukkan besarnya unsur tersebut $1 / 6$ dari batas yang diizinkan. Kadar logam berat terendah ditunjukkan pada unsur $\mathrm{Hg}$ yaitu $0.005 \mathrm{ppm}$ dan sangat rendah dibandingkan pada batas maksimal yang diizinkah. Hasil analisa keempat unsur tersebut menunjukkan kandungan logam berat pada pupuk tersebut masih di bawah batas aman sesuai dengan standar kualitas yang digunakan. Selain itu rendahnya kandungan logam berat mengindikasikan bahwa pupuk tersebut aman untuk digunakan untuk tanah dan tanaman.

Potensi dari fly ash sebagai bahan pupuk organik lebih kepada kemampuan dari material tersebut sebagai bahan pencampur pupuk organik. Potensi tersebut dapat dilihat dari kandungan Sililkat danAlumina (Tabel 1), dimana unsur tersebut merupakan salah satu agen sementasi yang baik. Harapannya apabila pupuk organik yang diberi bahan fly ash tersebut dapat menahan kehilangan air dan unsur hara dari tanah apabila pupuk tersebut di aplikasikan pada tanah dengan porositas yang tinggi seperti tanah dengan tekstur berpasir.

\section{KESIMPULAN}

Unsur dominan penyusun fly ash yang digunakan berupa besi oksida sebesar 71.2 $\%$, kemudian baru diikuti silikat dan alumina yaitu $16.2 \%$ dan $7.67 \%$. Penggunaan fly ash sebagai campuran bahan pupuk organik mampu meningkatkan $\mathrm{pH}$ pupuk yaitu dengan $\mathrm{pH}$ sebesar 8.52 . Penggunaan fly ash tidak memberikan efek pada besarnya kandungan $\mathrm{N}, \mathrm{P}$ dan $\mathrm{K}$. Besarnya kandungan NPK pada pupuk organik yang dihasilkan lebih dipengaruhi dari bahan organik lain yang digunakan, seperti daun leguminosa, ares batang pisang dan serbuk gergaji. Nilai positif dari penggunaan fly ash sebagai bahan pupuk organik yaitu tidak berpotensi meracuni tanah karena mempunyai kandungan logam berat yang rendah yaitu jauh dibawah dari nilai/batas yang diizinkan pada standar mutu pupuk organik.Oleh karena itu, fly ash berpotensi untuk digunakan dalam bidang pertanian sebagai pupuk organik yang dapat mengurangi kehilangan air dan unsur hara pada tanah dengan tekstur pasiran. 


\section{DAFTAR PUSTAKA}

Ardha, N. 2003. Pemanfaatan Abu Terbang PLTU-Suralaya Untuk Castable Refractory (Penelitian Pendahuluan). Litbang Pengolahan Mineral, Jakarta.

Brown, B.L., S. Bradshaw., T.B Edil., C.H Benson. 2015. Leaching from Roadways Stabilized with Fly ash: Data Assessment and Synthesis. World of Coal Ash (WOA) Conference in Nasvhille. TN May 57.

Garavaglia R and Caramuscio P. 1994. Coal Fly ash Leaching Behavior And Solubility Controlling Solids. In Proceeding Of The International Conference On Environmental Implications Of Construction Materials And Technology Developments ; Environmental Aspects of Construction Waste Management. Netherland

Kementerian ESDM. 2016. Rencana Usaha Penyediaan Tenaga Listrik PT. Perusahaan Listrik Negara (PLN) Tahun 2016 s.d Tahun 2025.

Komilis D.P and I.S Tziouvaras (2009). A Statistical Analysis to Assess the Maturity and Stability of Six Composts. Journal of Waste Management 29 : pp 1504-1513

Maryoto, A. 2008. Pengaruh Penggunaan High Volume Fly ash pada Kuat Tekan Mortar. Jurnal Teknik Sipil \& Perencanaan, Nomor 2 Volume 10 , hal 103-114.

Saraiva, B., Pacheco, E.B.V., Visconte, L.L.Y., Bispo, E.P., Escócio, V.A., de Sousa, A.M.F., Soares, A.G., Junior, M.F., Motta, L.C.D.C., dan Brito, G.F.D.C. 2012. Potentials for Utilization of Post-Fiber Extraction Waste From Tropical Fruit Production in Brazil - the Example of Banana Pseudo-Stem. International Journal of Environment and Bioenergy. 4 (2) : $101-119$.
Umardani, Y dan E.Sudrajat. 2007. Analisa

Penggunaan Fly ash Sebagai

Material Dasar Pengganti Cetakan Pasir Pada Pengecoran Besi Cor Ditinjau Dari Komposisi Campuran Cetakan

Utami, S.W., B.H Sunarminto, E. Hanudin. 2014. Pengaruh Limbah Biogas Sapi terhadap Ketersediaan Hara MakroMikro Inceptisol. Jurnal Tanah dan Air Volume 11 No 1 ISSN 14115719

Widyaningsih, S., E.Setyawan. dan T. Setyaningtyas. 2011. Karakterisasi Abu Terbang PLTU Cilacap Untuk Menurunkan Kesadahan Air di Desa Darmakradenan Kecamatan Ajibarang Kabupaten Banyumas. Molekul Volume 6 No 1: 35-39

Yazdanpanah, M., M. Mahmoodabadi, A. Cerda. 2016. The Impact of Organic Amandments on Soil Hydrology, Structure and Microbial Respiration in Semiarid Lands. Geoderma (266) : $58-65$

Zuraida. 2013. Penggunaan Berbagai Jenis Bahan Amelioran Terhdap Sifat Kimia Bahan Tanah Gambut Hemik. J.Floratek (8) : $101-109$ 